\title{
Residential distance at birth from overhead high-voltage powerlines: childhood cancer risk in Britain 1962-2008
}

\author{
K J Bunch*,1, T J Keegan ${ }^{2}$, J Swanson ${ }^{3}$, T J Vincent ${ }^{1}$ and M F G Murphy ${ }^{1}$ \\ ${ }^{1}$ Childhood Cancer Research Group, University of Oxford, New Richards Building, Old Road Campus, Headington, Oxford OX3 \\ 7LG, UK; ${ }^{2}$ Lancaster Medical School, Lancaster University, Furness Building, Lancaster LA1 4YA, UK and ${ }^{3}$ National Grid, 1-3 Strand, \\ London WC2N 5EH, UK
}

Background: We extend our previous study of childhood leukaemia and proximity to high-voltage powerlines by including more recent data and cases and controls from Scotland, by considering 132-kV powerlines as well as 275 and $400 \mathrm{kV}$ and by looking at greater distances from the powerlines.

Methods: Case-control study using 53515 children from the National Registry of Childhood Tumours 1962-2008, matched controls, and calculated distances of mother's address at child's birth to powerlines at 132, 275, and $400 \mathrm{kV}$ in England, Wales and Scotland.

Results: Our previous finding of an excess risk for leukaemia at distances out to $600 \mathrm{~m}$ declines over time. Relative risk and $95 \%$ confidence interval for leukaemia, 0-199 m compared with >1000 m, all voltages: 1960s 4.50 (0.97-20.83), 2000s 0.71 (0.49-1.03), aggregate over whole period 1.12 (0.90-1.38). Increased risk, albeit less strong, may also be present for 132-kV lines. Increased risk does not extend beyond $600 \mathrm{~m}$ for lines of any voltage.

Conclusions: A risk declining over time is unlikely to arise from any physical effect of the powerlines and is more likely to be the result of changing population characteristics among those living near powerlines.

Exposure to power-frequency electric and magnetic fields (EMFs) and associated risks of various diseases have been studied for $>30$ years. Laboratory evidence has been largely negative (IARC Working Group on the Evaluation of Carcinogenic Risks to Humans, 2002; World Health Organization, 2007), and no plausible biological mechanisms have been identified (Swanson and Kheifets, 2006), though candidates remain, for example, 'freeradicals' (Atkins, 1976; Brocklehurst and McLauchlan, 1996). Epidemiological studies have provided inconsistent support for a link between EMFs and various diseases (IARC Working Group on the Evaluation of Carcinogenic Risks to Humans, 2002; World Health Organization, 2007; Kheifets et al, 2010b; Elliott et al, 2013), but a relatively consistent association has been found for magnetic fields and childhood leukaemia (Ahlbom et al, 2000; Greenland et al, 2000; Kheifets et al, 2010a).
The epidemiological evidence for effects on health from exposure to power-frequency electric fields is largely negative (World Health Organization, 2007; Kheifets et al, 2010c). The remaining concern is principally with power-frequency magnetic fields, which are classified as 'possibly carcinogenic' (IARC Working Group on the Evaluation of Carcinogenic Risks to Humans, 2002; World Health Organization, 2007), and with residential proximity to high-voltage powerlines, which are one source of such fields.

In 2005, we reported a relationship of childhood leukaemia risk 1962-95 in England and Wales (E\&W) with distance of mother's usual residence at the time of birth of the child from the National Grid plc (NG) overhead powerlines (all 400/275-kV powerlines in $\mathrm{E} \& W$ plus a small fraction of $132-\mathrm{kV}$ lines) (Draper et al, 2005). Leukaemia risk was increased within $600 \mathrm{~m}$ of the lines, compared 
with those residing beyond $600 \mathrm{~m}$. No corresponding pattern of risk was found for central nervous system (CNS) tumours or the grouping of other childhood solid tumours. A clearly separable relationship of increasing leukaemia risk with higher socioeconomic status (SES) was also evident and persists in more recent analyses (Kroll et al, 2011b; Keegan et al, 2012). A subsequent report found an increased risk for leukaemia with calculated magnetic fields generated by the powerlines, based on very small numbers and not statistically significant but consistent with the relative risk of around 2 for fields $>0.4 \mu \mathrm{T}$ found in pooled analyses (Kroll et al, 2010). The United Kingdom Childhood Cancer Study (UK Childhood Cancer Study Investigators, 2000b) reported a smaller study of childhood leukaemias and other cancers across England, Wales and Scotland, which both measured magnetic fields within the home from all sources and calculated distances to powerlines. It also reported elevated risks for leukaemia that were not statistically significant, though they were compatible with the pooled analyses for magnetic fields and with the Draper et al (2005) results for powerline proximity (UK Childhood Cancer Study Investigators, 1999, 2000a; Draper et al, 2005).

Attempts have been made to establish whether the report by Draper et al (2005) of an association of childhood leukaemia with residential proximity to overhead powerlines, specifically at distances out to $600 \mathrm{~m}$, which had not previously been reported, could be replicated. A study in France (Sermage-Faure et al, 2013) found elevated risks within $50 \mathrm{~m}$, confined to the higher-voltage lines and to younger children but not extending beyond $50 \mathrm{~m}$; a study in Denmark (Pedersen et al, 2014) found no overall pattern of increased risk; and a study in California is in progress. We therefore report here the most powerful analysis it has been feasible for us to construct using methodology similar to that of our previous report. We have extended our previous study to include data relating to cases diagnosed up to the end of 2008 (and controls) in E\&W and cases and controls from Scotland for the whole period 1962-2008. Importantly, the analyses have also been extended to include consideration of $132-\mathrm{kV}$ overhead powerlines as well as $400 / 275 \mathrm{kV}$ and to evaluate risk at distances between 600 and $1000 \mathrm{~m}$.

This paper presents risk analyses for residential distance at birth from these powerlines, which may be of aetiological interest in its own right, not just as a surrogate for the magnetic fields produced by the powerlines. We will present risk analyses in relation to calculated magnetic fields separately.

\section{MATERIALS AND METHODS}

Cases and controls. The UK National Registry of Childhood Tumours (NRCT) has recorded nearly all childhood cancers (malignancies and brain/CNS tumours whose behaviour may be benign or uncertain) occurring since 1962 in those diagnosed under the age of 15 years while domiciled in England, Wales and Scotland (Britain) (Kroll et al, 2011a, 2012).

In the registration years considered complete at the time of this study (1962-2008), 57067 tumours were registered on the NRCT as occurring in children in England, Wales and Scotland. The publicly available part of the birth registration information is obtained routinely for about $94 \%$ of all those registered on the NRCT (unless born outside Britain, adopted or because of failure to trace at the NHS Central Registers). We therefore obtained mother's residential address at birth for 53515 children registered on the NRCT 1962-2008.

For every childhood cancer case whose birth registration could be traced, a birth record was also obtained for at least one control child (known to be unaffected by cancer as determined by absence from the NRCT at the time of selection) matched for sex, approximate date of birth and birth registration sub-district. There were some 430 birth registration districts and 1700 sub-districts of varying sizes across England, Wales and Scotland over the period covered by our study.

For those registered with cancer from the year 2000, two control birth records were obtained. Previously one only was identified by systematic sampling up or down in the birth register from the case's entry, depending on whether the case's NRCT registration number was odd or even. Now two controls are selected by moving at least six entries up and down the birth register from the case and selecting the next matching birth. Controls are nearly always available within the same sub-district register with a date of birth within 6 months of the case's date of birth. A few controls may have died or emigrated before the date of diagnosis of their matched case, but otherwise we believe the controls are essentially unbiased in their availability, and any limitations have minimal implications. Hence we obtained birth registration data for 66204 control children.

Calculation of distance from powerlines. Grid references of case/control mothers' residence at time of birth of the child and of overhead powerlines were used to calculate distances, using the same methods as we used previously (Draper et al, 2005; Swanson, 2008), with minor differences, described in the following paragraphs, mainly forced by the form of the new data available to us.

Grid references for the $400 / 275 \mathrm{kV}$ and $143 \mathrm{~km}$ of the $132-\mathrm{kV}$ transmission powerlines in $\mathrm{E} \& \mathrm{~W}$ were provided by $\mathrm{NG}$. We obtained grid references for the remaining $132-\mathrm{kV}$ distribution lines in E\&W from the then seven Distribution Network Operators (DNOs, listed in Acknowledgements), which between them covered the 12 geographically based licence areas into which E\&W are divided. Data for 400/275/132-kV lines in Scotland were obtained from the two DNOs, which also cover the two Scottish licence areas. For 4 of the 14 licence areas covering Britain, grid references of pylons or poles with connections between them in the correct sequence were provided. For the remaining 10, we had only the pylon/pole grid references without connections, and we assigned connections automatically using the largely sequential numbering system for pylons, with manual checks and corrections where indicated by obvious discrepancies or implausibilities. We sought information on year of construction and, for 7 of the 14 licence areas (including both in Scotland), were able to identify a year of construction for $>80 \%$ of spans. Across these seven licence areas, we had year of construction for $93 \%$ of $132-\mathrm{kV}$ spans and, across the whole study area, $99 \%$ of $400 / 275-\mathrm{kV}$ spans. For those $132-\mathrm{kV}$ lines where we did have year of construction, $67 \%$ predated our study period, which therefore gives an indication of the error rate produced by assuming powerlines were present if no construction date was available. In total, this study includes data for $11058 \mathrm{~km}$ of $400 / 275-\mathrm{kV}$ and $15810 \mathrm{~km}$ of $132-\mathrm{kV}$ lines.

For $98 \%$ (117583) of addresses, we were able to allocate a postcode, and for 94\% (110639) of these cases and controls, we were also able to add the Address-Point (Ordnance Survey, Southampton, UK) grid reference of their home. The AddressPoint grid reference is a $0.1-\mathrm{m}$ resolution grid reference located somewhere within the footprint of the building concerned; in this study, we did not attempt to locate where within the building it lay. For those homes ( $6 \%$ of subjects) where we had only the grid reference of the centroid of the postcode, if the distance calculated from the postcode centroid to the powerline was $>1500 \mathrm{~m}$, we could reliably assume that all the houses within that postcode were at least $1000 \mathrm{~m}$ from the line. If the distance calculated from the postcode centroid to the powerline was $\leqslant 1500 \mathrm{~m}$, the distance was treated as missing because of the uncertainty involved, stemming from the spatial extent of the postcode. 
We calculated, from the grid references using coordinate geometry, blind to case-control status, the shortest distance to the nearest overhead powerline that existed in the year of birth, assuming that the line did exist if the year of construction was not available, for England, Wales and Scotland, separately for 400/275- and 132-kV lines.

Measures of socioeconomic status. Because we have repeatedly demonstrated associations of childhood cancer risk (particularly for leukaemia) with different measures of SES, some distance analyses were repeated adjusting for this variable, to ensure that any distance relationship observed was not a simple consequence of a relation between distance and SES. To do this, we used quintiles of the Carstairs deprivation index to allocate a 1981 measure of SES to the census ward in which each case or control resided at birth. Census wards vary in geographical size and population, and there were 10444 such wards in England, Wales and Scotland at the 1981 census.

Statistical analysis. We analysed the distance between residential address and powerline location for cases and matched controls using conditional logistic regression. Distance bands for analysis were those used in our previous study (Draper et al, 2005) and other studies (e.g., Sermage-Faure et al, 2013), together with prespecified $100-\mathrm{m}$ bands from $600 \mathrm{~m}$ out to $1000 \mathrm{~m}$ from the powerlines. The conditional logistic regression analyses were implemented in STATA Version 11 (StataCorp., College Station, TX, USA).

\section{RESULTS}

Supplementary Data Table S1 reports the results of using the distance and case-control data for E\&W available in 2012, for the period 1962-95, against the results for the same period as analysed about 10 years ago and reported in 2005. Over the decade elapsing between construction of the two data files relevant to 1962-95, there have been changes in the definition of childhood cancer cases. These arise from the implementation of the third edition of the International Classification of Diseases for Oncology (ICD-O-3) and the related third edition of the International Classification of Childhood Cancer (ICCC-3). Overall, there has been an increase in the number of eligible cancer cases on the NRCT for 1962-95 (2\% increase in eligible case-control pairs for leukaemia of which $1.5 \%$ arose from re-categorisation of myelodysplastic syndrome as a malignancy in ICCC-3; $2 \%$ increase for CNS tumours; $0.5 \%$ increase for other solid tumours).

In all subsequent analyses, there were some sporadic elevated or reduced risks for CNS tumours in some year/distance categories, and some of these are statistically significant. To a lesser extent, this is also the case for 'other solid tumours'. However, these variations in risks do not form any pattern, and we consider them likely to be chance findings. Our following presentation of results therefore concentrates on leukaemia; however, results for both CNS and other solid tumours are shown in the Supplementary Data Tables. There were occasional significant results in analyses of subsets of the data, for example, $1 / d, 1 / d^{2}$ for leukaemia in E\&W alone in the period 1996-2008, but they are counterintuitive, indicating increased risk with increased distance, and we are inclined to regard them also as due to chance. We have also conducted all analyses adjusting for SES, but this made no appreciable difference to any of the results (not shown), so, for simplicity, we present only the unadjusted findings.

Table 1 (expanded version at Supplementary Data Tables S2a-c) reports the distance analyses for cases (diagnosed in 1962-2008) and one or two matched controls resident in Britain in relation to $400 / 275-\mathrm{kV}$ powerlines for distances out to $1000 \mathrm{~m}$, with those resident $\geqslant 1000 \mathrm{~m}$ as reference. Exclusion of data for Scotland or the data for second controls makes no difference (not shown). Over the whole period, there is no evidence of a distance effect for any of the three cancer groups. However, when stratified by decade of occurrence (1962-69 to 2000-08) there is evidence that leukaemia risk in those living within $600 \mathrm{~m}$ of a powerline was raised between 1962-79, declining thereafter. Elevated risk persisted in the 1980s but was not statistically significant. Even in the decades when the risk appears to be present, there is no evidence that it extended beyond the $600 \mathrm{~m}$ outer limit of the original analysis.

Supplementary Data Tables S3a-c reports the distance analyses for cases (diagnosed in 1962-2008) and matched controls resident in Britain in relation only to $132-\mathrm{kV}$ powerlines for distances out to $1000 \mathrm{~m}$ with those resident $\geqslant 1000 \mathrm{~m}$ as reference. There are some indications of raised risks for leukaemia within $200 \mathrm{~m}$, reducing (as for 400/275-kV lines) across the decades, but none of the risks are statistically significant. This analysis uses data relating to only the seven licence areas with $>80 \%$ information on construction date of the lines on the basis that it is better to restrict to more robust data even at the cost of statistical power. Results for all 14 licence areas (not presented) give even less indication of any effects.

Table 2 (expanded version at Supplementary Data Tables S4a-c) reports the distance analyses for cases (diagnosed in 1962-2008) and matched controls resident in Britain in relation to the nearest powerline of any of the voltages included in this study (across the whole of England, Wales and Scotland for $400 / 275-\mathrm{kV}$ powerlines, but only those licence areas with $>80 \%$ known construction years for $132 \mathrm{kV}$ ). These overall risks within $600 \mathrm{~m}$ are also presented in Figure 1. Over the whole period, there is no excess risk, but risks in the earlier decades suggest an excess for leukaemia within $600 \mathrm{~m}$, larger than in our original report, which was the aggregate over $1962-1995$, and also largely based on $400 / 275-\mathrm{kV}$ powerlines only (Draper et al, 2005).

\section{DISCUSSION}

Using the updated NRCT case-control data set and information from NG available in 2012, we were able to replicate the excess risk for childhood leukaemia reported in 2005 for distances within $600 \mathrm{~m}$ of $400 / 275-\mathrm{kV}$ (and some $132 \mathrm{kV}$ ) overhead powerlines in E\&W over the period 1962-95. The similarity of our present reanalysis and original findings, despite changes in cancer classifications, confirms that our methods are reproducible. Using more recent data up to 2008, we did not detect in the 1990s and 2000s the significant risks we previously noted despite having adequate power to do so. Our new results suggest the excess risk was in fact present only in the earlier decades, up to and including the 1970s and possibly the 1980s, but not in the later decades and is not evident when the cases and controls are analysed in aggregate across Britain from 1962 to 2008. These early risks presumably dominated the findings to 1995 we previously presented, although no temporal trend was then investigated (Draper et al, 2005). The excess does not appear to extend beyond the $600 \mathrm{~m}$ of the original analysis of predominately $400 / 275-\mathrm{kV}$ lines. There is no evidence that the situation in Scotland is different to E\&W. There are suggestions that elevated risks are also present for the $132-\mathrm{kV}$ lines, possibly confined to smaller distances, and similarly only in the earlier decades, but none of the results for $132-\mathrm{kV}$ lines within $600 \mathrm{~m}$ are statistically significant. There is no obvious increase in risk or pattern of risks with distance for tumour groups other than leukaemia.

Previous studies reported that leukaemia risk increased with affluence (Kroll et al, 2011b). Similarly, measures of SES based on paternal occupation have shown an association between higher social class and leukaemia risk (Keegan et al, 2012). The two measures (Carstairs deprivation score, occupational social class) 
Table 1. Distance of address at birth from the nearest 400/275-kV line within each decade of diagnosis and in aggregate for cases diagnosed from 1962 to 2008 (and controls) in England, Wales and Scotland (expanded version available at Supplementary Tables S2a-c)

\begin{tabular}{|c|c|c|c|c|c|c|c|c|c|c|c|c|}
\hline & \multicolumn{4}{|c|}{ Leukaemia } & \multicolumn{4}{|c|}{ CNS/brain tumours } & \multicolumn{4}{|c|}{ Other solid tumours } \\
\hline Distance to line (m) & Cases & Controls & RR & $95 \% \mathrm{Cl}$ & Cases & Controls & RR & $95 \% \mathrm{Cl}$ & Cases & Controls & RR & $95 \% \mathrm{Cl}$ \\
\hline \multicolumn{13}{|l|}{$1962-1969$} \\
\hline $0-199$ & 5 & 1 & $\infty$ & & 0 & 3 & 0.00 & & 3 & 3 & 0.67 & $0.11-3.99$ \\
\hline $200-599$ & 22 & 9 & 2.50 & $1.10-5.68$ & 6 & 4 & 1.50 & $0.42-5.32$ & 23 & 22 & 1.06 & $0.55-2.01$ \\
\hline $600-999$ & 23 & 30 & 0.76 & $0.40-1.46$ & 9 & 10 & 0.88 & $0.32-2.41$ & 22 & 37 & 0.59 & $0.34-1.02$ \\
\hline$\geqslant 1000$ (ref.) & 1088 & 1098 & & & 603 & 601 & & & 1570 & 1556 & & \\
\hline Total & 1138 & 1138 & & & 618 & 618 & & & 1618 & 1618 & & \\
\hline \multicolumn{13}{|l|}{ 1970-1979 } \\
\hline $0-199$ & 22 & 7 & 2.83 & $1.12-7.19$ & 4 & 10 & 0.44 & $0.14-1.44$ & 11 & 18 & 0.44 & $0.18-1.06$ \\
\hline $200-599$ & 73 & 79 & 0.91 & $0.65-1.29$ & 51 & 42 & 1.22 & $0.79-1.90$ & 93 & 79 & 1.12 & $0.81-1.56$ \\
\hline 600-999 & 123 & 112 & 1.17 & $0.88-1.55$ & 59 & 76 & 0.73 & $0.50-1.07$ & 132 & 120 & 1.21 & $0.92-1.58$ \\
\hline$\geqslant 1000$ (ref.) & 3357 & 3377 & & & 2212 & 2198 & & & 3902 & 3925 & & \\
\hline Total & 3575 & 3575 & & & 2326 & 2326 & & & 4138 & 4142 & & \\
\hline \multicolumn{13}{|l|}{ 1980-1989 } \\
\hline $0-199$ & 18 & 9 & 1.56 & $0.67-3.59$ & 20 & 19 & 0.88 & $0.43-1.79$ & 23 & 32 & 0.59 & $0.32-1.10$ \\
\hline $200-599$ & 112 & 84 & 1.39 & $1.01-1.90$ & 76 & 61 & 1.38 & $0.92-2.05$ & 146 & 139 & 1.08 & $0.84-1.39$ \\
\hline $600-999$ & 148 & 171 & 0.89 & $0.70-1.13$ & 99 & 107 & 0.95 & $0.71-1.27$ & 215 & 214 & 1.00 & $0.81-1.23$ \\
\hline$\geqslant 1000$ (ref.) & 3336 & 3359 & & & 2370 & 2392 & & & 4592 & 4608 & & \\
\hline Total & 3614 & 3623 & & & 2565 & 2579 & & & 4976 & 4993 & & \\
\hline \multicolumn{13}{|l|}{ 1990-1999 } \\
\hline $0-199$ & 33 & 42 & 0.71 & $0.43-1.17$ & 27 & 20 & 1.16 & $0.60-2.24$ & 39 & 39 & 0.87 & $0.53-1.43$ \\
\hline $200-599$ & 129 & 152 & 0.90 & $0.69-1.17$ & 86 & 96 & 0.88 & $0.63-1.22$ & 183 & 186 & 1.00 & $0.80-1.25$ \\
\hline 600-999 & 169 & 168 & 0.99 & $0.78-1.25$ & 138 & 136 & 1.12 & $0.86-1.46$ & 234 & 256 & 0.95 & $0.78-1.15$ \\
\hline$\geqslant 1000$ (ref.) & 3966 & 3997 & & & 2965 & 3046 & & & 5254 & 5368 & & \\
\hline Total & 4297 & 4359 & & & 3216 & 3298 & & & 5710 & 5849 & & \\
\hline \multicolumn{13}{|l|}{ 2000-2008 } \\
\hline $0-199$ & 27 & 60 & 0.78 & $0.48-1.27$ & 28 & 44 & 1.17 & $0.71-1.95$ & 43 & 77 & 1.17 & $0.78-1.76$ \\
\hline $200-599$ & 147 & 260 & 1.10 & $0.88-1.37$ & 107 & 172 & 1.21 & $0.93-1.57$ & 170 & 315 & 1.05 & $0.86-1.28$ \\
\hline $600-999$ & 182 & 340 & 1.01 & $0.83-1.22$ & 138 & 270 & 1.02 & $0.82-1.27$ & 252 & 491 & 0.99 & $0.84-1.17$ \\
\hline$\geqslant 1000$ (ref.) & 3650 & 7074 & & & 2970 & 5829 & & & 5078 & 9864 & & \\
\hline Total & 4006 & 7734 & & & 3243 & 6315 & & & 5543 & 10747 & & \\
\hline \multicolumn{13}{|l|}{ 1962-2008 } \\
\hline 0-199 & 105 & 119 & 1.00 & $0.75-1.34$ & 79 & 96 & 0.96 & $0.69-1.34$ & 119 & 169 & 0.85 & $0.65-1.10$ \\
\hline 200-599 & 483 & 584 & 1.08 & $0.95-1.24$ & 326 & 375 & 1.15 & $0.97-1.35$ & 615 & 741 & 1.05 & $0.94-1.18$ \\
\hline 600-999 & 645 & 821 & 0.99 & $0.88-1.11$ & 443 & 599 & 0.98 & $0.86-1.12$ & 855 & 1118 & 0.99 & $0.90-1.09$ \\
\hline$\geqslant 1000$ (ref.) & 15397 & 18905 & 1.00 & & 11120 & 14066 & 1.00 & & 20396 & 25321 & 1.00 & \\
\hline Total & 16630 & 20429 & & & 11968 & 15136 & & & 21985 & 27349 & & \\
\hline
\end{tabular}

are poorly correlated but converge in suggesting that, in unbiased national studies in the UK, childhood leukaemia risk is associated with affluence (Kendall et al, 2013a, b). However, adjusting our analyses using the Carstairs measure made very little difference to our results.

Our previous results for calculated magnetic fields (Kroll et al, 2010) demonstrated that magnetic fields could not be the sole or even the main explanation for the excess leukaemia risk we reported within $600 \mathrm{~m}$ (Draper et al, 2005). This is reinforced by results presented here to 2008 , as it is implausible that any biophysical effect of magnetic fields would change over time. Nor have the fields the lines produce reduced over this period; using data collected for our magnetic-field calculations, we calculated that the average loads carried by the relevant NG lines (which, distance-for-distance, determines the magnetic field) in fact increased by $76 \%$ from the 1960 s to the 2000 s.

The 'corona ion hypothesis' (Fews et al, 1999) notes that the air ions produced by the electric fields of powerlines blow away from the lines and attach to existing airborne pollutants, increasing the charge of the pollutants, and hence the rate at which they are absorbed when breathed in and the resulting dose to the body. This could produce an effect diminishing over time if the concentration of relevant leukaemogenic pollutants also reduced over time. Some, though not all, pollutants have indeed reduced over the relevant 
Table 2. Distance of address at birth within each decade of diagnosis and in aggregate from the nearest line: 400/275 kV (all companies) or $132 \mathrm{kV}$ (from companies with $>80 \%$ data) for cases diagnosed from 1962 to 2008 (and controls) in England, Wales and Scotland (expanded version available at Supplementary Data Tables S4a-c)

\begin{tabular}{|c|c|c|c|c|c|c|c|c|c|c|c|c|}
\hline & \multicolumn{4}{|c|}{ Leukaemia } & \multicolumn{4}{|c|}{ CNS/brain tumours } & \multicolumn{4}{|c|}{ Other solid tumours } \\
\hline Distance to line $(\mathrm{m})$ & Cases & Controls & $\mathrm{RR}$ & $95 \% \mathrm{Cl}$ & Cases & Controls & RR & $95 \% \mathrm{Cl}$ & Cases & Controls & $\mathbf{R R}$ & $95 \% \mathrm{Cl}$ \\
\hline \multicolumn{13}{|l|}{ 1962-1969 } \\
\hline 0-199 & 14 & 4 & 4.50 & $0.97-20.83$ & 1 & 5 & 0.25 & $0.03-2.24$ & 11 & 9 & 0.88 & $0.32-2.41$ \\
\hline $200-599$ & 34 & 26 & 1.33 & $0.76-2.35$ & 17 & 16 & 0.92 & $0.40-2.08$ & 45 & 54 & 0.82 & $0.51-1.31$ \\
\hline 600-999 & 48 & 53 & 0.97 & $0.61-1.54$ & 24 & 24 & 1.05 & $0.56-1.97$ & 60 & 79 & 0.70 & $0.48-1.04$ \\
\hline$\geqslant 1000$ (ref.) & 1011 & 1024 & 1.00 & & 565 & 562 & 1.00 & & 1464 & 1438 & 1.00 & \\
\hline Total & 1107 & 1107 & & & 607 & 607 & & & 1580 & 1580 & & \\
\hline \multicolumn{13}{|l|}{ 1970-1979 } \\
\hline 0-199 & 40 & 22 & 2.46 & $1.29-4.69$ & 17 & 23 & 0.67 & $0.32-1.38$ & 36 & 40 & 0.79 & $0.48-1.32$ \\
\hline $200-599$ & 141 & 147 & $\overline{0.94}$ & $0.72-1.23$ & 95 & 80 & 1.29 & $0.92-1.81$ & 174 & 160 & 1.12 & $0.87-1.44$ \\
\hline $600-999$ & 207 & 192 & 1.11 & $0.88-1.39$ & 123 & 120 & 1.01 & $0.76-1.35$ & 190 & 207 & 0.92 & $0.74-1.15$ \\
\hline$\geqslant 1000$ (ref.) & 3131 & 3158 & 1.00 & & 2051 & 2063 & 1.00 & & 3659 & 3656 & 1.00 & \\
\hline Total & 3519 & 3519 & & & 2286 & 2286 & & & 4059 & 4063 & & \\
\hline \multicolumn{13}{|l|}{ 1980-1989 } \\
\hline $0-199$ & 52 & 36 & 1.54 & $0.92-2.58$ & 49 & 37 & 1.21 & $0.74-2.00$ & 53 & 66 & 0.77 & $0.51-1.16$ \\
\hline $200-599$ & 180 & 161 & 1.13 & $0.88-1.44$ & 119 & 116 & 1.10 & $0.81-1.51$ & 253 & 246 & 1.03 & $0.84-1.26$ \\
\hline $600-999$ & 215 & 255 & 0.85 & $0.69-1.03$ & 170 & 157 & 1.12 & $0.88-1.44$ & 343 & 337 & 1.03 & $0.87-1.22$ \\
\hline$\geqslant 1000$ (ref.) & 3122 & 3126 & 1.00 & & 2188 & 2229 & 1.00 & & 4248 & 4265 & 1.00 & \\
\hline Total & 3569 & 3578 & & & 2526 & 2539 & & & 4897 & 4914 & & \\
\hline \multicolumn{13}{|l|}{ 1990-1999 } \\
\hline 0-199 & 67 & 64 & 0.99 & $0.66-1.49$ & 48 & 37 & 1.15 & $0.71-1.85$ & 77 & 85 & 0.88 & $0.60-1.28$ \\
\hline $200-599$ & 223 & 271 & 0.86 & $0.70-1.05$ & 154 & 167 & 0.98 & $0.76-1.27$ & 315 & 329 & 1.00 & $0.84-1.19$ \\
\hline 600-999 & 285 & 269 & 1.04 & $0.86-1.25$ & 238 & 215 & 1.18 & $0.96-1.46$ & 370 & 393 & 0.93 & $0.79-1.09$ \\
\hline$\geqslant 1000$ (ref.) & 3688 & 3721 & 1.00 & & 2747 & 2849 & 1.00 & & 4905 & 4998 & 1.00 & \\
\hline Total & 4263 & 4325 & & & 3187 & 3268 & & & 5667 & 5805 & & \\
\hline \multicolumn{13}{|l|}{ 2000-2008 } \\
\hline 0-199 & 48 & 113 & 0.71 & $0.49-1.03$ & 54 & 90 & 1.13 & $0.78-1.65$ & 80 & 156 & 1.07 & $0.79-1.46$ \\
\hline $200-599$ & 242 & 436 & 1.03 & $0.86-1.23$ & 174 & 306 & 1.10 & $0.89-1.35$ & 283 & 580 & 0.90 & $0.77-1.06$ \\
\hline 600-999 & 292 & 553 & 1.00 & $0.85-1.17$ & 227 & 454 & 1.01 & $0.84-1.20$ & 405 & 784 & 0.98 & $0.86-1.12$ \\
\hline$\geqslant 1000$ (ref.) & 3417 & 6610 & 1.00 & & 2784 & 5452 & 1.00 & & 4764 & 9194 & 1.00 & \\
\hline Total & 3999 & 7712 & & & 3239 & 6302 & & & 5532 & 10714 & & \\
\hline \multicolumn{13}{|l|}{ 1962-2008 } \\
\hline 0-199 & 221 & 239 & 1.12 & $0.90-1.38$ & 169 & 192 & 1.06 & $0.84-1.35$ & 257 & 356 & 0.91 & $0.75-1.09$ \\
\hline $200-599$ & 820 & 1041 & 0.99 & $0.89-1.10$ & 559 & 685 & 1.09 & $0.96-1.24$ & 1070 & 1369 & 0.98 & $0.89-1.07$ \\
\hline $600-999$ & 1047 & 1322 & 0.99 & $0.90-1.08$ & 782 & 970 & 1.07 & $0.97-1.20$ & 1368 & 1800 & 0.96 & $0.88-1.04$ \\
\hline$\geqslant 1000$ (ref.) & 14369 & 17639 & 1.00 & & 10335 & 13155 & 1.00 & & 19040 & 23551 & 1.00 & \\
\hline Total & 16457 & 20241 & & & 11845 & 15002 & & & 21735 & 27076 & & \\
\hline
\end{tabular}

time period (Murrells et al, 2010). However, no such leukaemogenic pollutants have been identified, analyses suggest any such effects are quantitatively insignificant (Advisory Group on NonIonising Radiation, 2004) and our previous results did not demonstrate the expected excess of leukaemia downwind of powerlines (Draper et al, 2005). We will present a better test of this hypothesis in a separate paper.

An alternative explanation (Draper et al, 2005; Swanson et al, 2006) is that the effect, when present, is not a direct physical effect but indirect, arising either as a consequence of the types of area powerlines have been built through or an effect existing powerlines have on the type of housing that is built nearby or the people who come to live there. This could be hypothesised to produce the change over time we observe in one of two ways. Either it could be a transient effect lasting a decade or two from the construction of a powerline, which might produce the observed change given that most powerlines were built in the $1950 \mathrm{~s} / 1960 \mathrm{~s}$, with the $132-\mathrm{kV}$ lines on average older. Alternatively, there could be a change in the types of houses built near powerlines, or the characteristics of the people living in them, over this period.

Another explanation of our previous results could be bias, perhaps in control selection (Draper et al, 2005; Swanson et al, 2006). We noted previously, and others emphasised (e.g. Kheifets et al, 2005), that fewer of our leukaemia controls lived near 


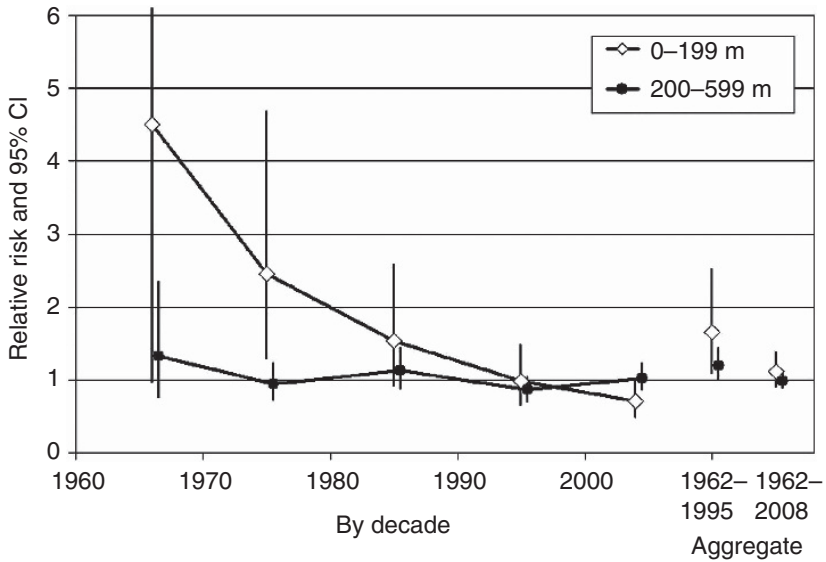

Figure 1. Relative risks of leukaemia by decade of birth in Britain, based on 132 ( $>80 \%$ year of construction information)/275/400-kV case-control exposure, by distance of residence from powerline. $1962-1995$ is the aggregate result from our previous study (275- and 400-kV powerlines, E\&W) as recalculated in this paper; 1962-2008, the aggregate result from this study, including $132-\mathrm{kV}$ powerlines and Scotland.

powerlines than the controls for other cancers, perhaps suggestive of a biased control group, either through a selection bias or through chance. The data in the Supplementary Tables indicate that this applied for $275 / 400-\mathrm{kV}$ lines in the earlier decades, coinciding with the increased risk, but applied much less to the $132-\mathrm{kV}$ lines, where there were also suggestions of increased risks. No mechanism for such a bias has been identified, and it is even harder to think of a bias that reduces over time, but bias remains a possibility in principle. Chance must also always remain a possible explanation, perhaps particularly considering the multiple testing we have undertaken.

Of the two other studies published looking specifically at the same 600-m distances, one (Sermage-Faure et al, 2013) did not find elevated risks beyond $50 \mathrm{~m}$ and covered a more limited and more recent timespan (2002-2007). The other, Pedersen et al (2014), covering 1968-2006, found an elevated risk between 200 and $600 \mathrm{~m}$ for the highest voltage powerlines, but because this was not statistically significant and did not form part of a pattern of elevated risks, suggested it was likely to be a chance finding.

The change in the pattern of leukaemia risks (with distance) over time that we have observed, suggesting a real (if not obviously explicable) effect in the earliest period of observation but disappearing in later years, is not unique to non-ionising radiation EMF epidemiology. We have observed, in an as yet unpublished analysis, a similar effect of excess leukaemia risk (but few other increased tumour risks) declining over time in the vicinity of point sources of potential exposure to ionising radiation at Sellafield and at Dounreay. The most convincing explanation in that instance lies in the changing population characteristics of those living and working in the vicinity over time, rather than emanations from the nuclear plant.

Finally, this is the first ever investigation to consider specifically whether there are any risks to those living between 600 and $1000 \mathrm{~m}$ from overhead powerlines. Our results suggest little or no basis for concern. Although we reported risks in 2005 for those living within $600 \mathrm{~m}$ of $400 / 275-\mathrm{kV}$ powerlines in the period $1962-95$, the population living this close to powerlines is small. Therefore, given the size of the increased risk detected, very few childhood leukaemia cases per year could possibly be attributed to this residential feature. Clearly, the population living within $1000 \mathrm{~m}$ of a powerline is larger than that living closer, so it is reassuring that no risks have ever been evident outside $600 \mathrm{~m}$.

\section{CONCLUSIONS}

We previously reported elevated risks for leukaemia in children born and diagnosed from 1962 to 1995 within $600 \mathrm{~m}$ of 400/275-kV powerlines. Our new data presented here suggest a lesser elevation may occur for the $132-\mathrm{kV}$ powerlines. Increased risk does not extend beyond $600 \mathrm{~m}$ for lines of any voltage. Risk appears to have declined over the period from 1962 to 2008 in Britain, and in aggregate over that period, there is no significant excess risk.

The strengths of our study are its size, objective assessment of proximity to powerlines and freedom from any obvious source of bias. The result almost certainly cannot be produced by powerlinegenerated magnetic fields and is unlikely to be due to any other physical emanation from the lines. If the result is not due to study artefact or chance, the only remaining possibility seems to lie in changing population characteristics of people living near powerlines.

\section{ACKNOWLEDGEMENTS}

The Childhood Cancer Research Group (CCRG), housing the UK National Registry of Childhood Tumours, has historically received core support from the Department of Health for England and Wales, National Cancer Intelligence Network and the Scottish Government. The research work described here was funded by a Programme Grant awarded from Children with Cancer UK. Powerline data in England and Wales were provided by National Grid, CE Electric UK (now Northern Powergrid), Central Networks (now part of Western Power Distribution), EDF Energy Networks (now UK Power Networks), Electricity North West, Western Power Distribution, SSE and Scottish Power (the last two covering Scotland as well). We thank the Royal Mail and Ordnance Survey for making the Address-Point data available (Crown Copyright. All rights reserved). No funding agency, or the University of Oxford as research sponsor, played any part in the decision to submit the paper for publication, and the views expressed are those of the authors alone. JS worked on this paper with permission from National Grid, but no results were shared, nor was approval sought from anyone in National Grid and the views expressed are his alone. We are grateful to CCRG colleagues, particularly Gerald Draper and Charles Stiller, for helpful discussions.

\section{REFERENCES}

Advisory Group on Non-Ionising Radiation (2004) Particle Deposition in the Vicinity of Power Lines and Possible Effects on Health. National Radiological Protection Board. Documents of the NRPB: Chilton, UK.

Ahlbom A, Day N, Feychting M, Roman E, Skinner J, Dockerty J, Linet M, McBride M, Michaelis J, Olsen JH, Tynes T, Verkasalo PK (2000) A pooled analysis of magnetic fields and childhood leukaemia. Br J Cancer 83(5): 692-698.

Atkins P (1976) Magnetic field effects. Chem Britain 12(7): 214-218.

Brocklehurst P, McLauchlan KA (1996) Free radical mechanisms for the effects of environmental electromagnetic fields on biological systems. Int J Radiat Biol 69: 3-24.

Draper G, Vincent T, Kroll ME, Swanson J (2005) Childhood cancer in relation to distance from high voltage power lines in England and Wales: a case-control study. BMJ 330(7503): 1290-1294.

Elliott P, Shaddick G, Douglas M, de Hoogh K, Briggs DJ, Toledano MB (2013) Adult cancers near high voltage overhead power lines. Epidemiology 24(2): 184-190.

Fews AP, Henshaw DL, Wilding RJ, Keitch PA (1999) Corona ions from powerlines and increased exposure to pollutant aerosols. Int J Radiat Biol 75(12): 1523-1531. 
Greenland S, Sheppard AR, Kaune WT, Poole C, Kelsh MA (2000) A pooled analysis of magnetic fields, wire codes, and childhood leukemia. Epidemiology (Cambridge, Mass) 11(6): 624-634.

IARC Working Group on the Evaluation of Carcinogenic Risks to Humans (2002) Monographs on the Evaluation of Carcinogenic Risks to Humans: Non-Ionizing Radiation Part 1: Static and Extremely Low-Frequency (ELF) Electric and Magnetic Fields. IARC press: Lyon, France.

Keegan TJ, Bunch KJ, Vincent TJ, King JC, O’Neill KA, Kendall GM, MacCarthy A, Fear NT, Murphy MFG (2012) Case-control study of paternal occupation and risk of childhood leukaemia in Great Britain, 1962-2006. Br J Cancer 107(9): 1652-1659.

Kendall GM, Bunch KJ, JCHM Miles, Vincent TJ, Little MP, Wakeford R, Meara JR, Murphy MFG (2013a) Report of a Record-Based Case-Control Study of Natural Background Radiation and Incidence of Childhood Cancer in Great Britain. Health Protection Agency: Chilton, Didcot, UK.

Kendall GM, Little MP, Wakeford R, Bunch KJ, Miles JCH, Vincent TJ, Meara JR, Murphy MFG (2013b) A record-based case-control study of natural background radiation and the incidence of childhood leukaemia and other cancers in Great Britain during 1980-2006. Leukemia 27(1): 3-9.

Kheifets L, Ahlbom A, Crespi CM, Draper G, Hagihara J, Lowenthal RM, Mezei G, Oksuzyan S, Schüz J, Swanson J, Tittarelli A, Vinceti M, Wunsch Filho V (2010a) Pooled analysis of recent studies on magnetic fields and childhood leukaemia. Br J Cancer 103(7): 1128-1135.

Kheifets L, Ahlbom A, Crespi CM, Feychting M, Johansen C, Monroe J, Murphy MF, Oksuzyan S, Preston-Martin S, Roman E, Saito T, Savitz D, Schüz J, Simpson J, Swanson J, Tynes T, Verkasalo P, Mezei G (2010b) A pooled analysis of extremely low-frequency magnetic fields and childhood brain tumors. Am J Epidemiol 172(7): 752-761.

Kheifets L, Feychting M, Schuz J (2005) Control selection in the study of childhood cancer in relation to distance from high voltage power lines in England and Wales. BMJ Rapid Responses. Available at www.bmj.com/rapid-response/2011/10/31/control-selectionstudy-childhood-cancer-relation-distance-high-voltage-po.

Kheifets L, Renew D, Sias G, Swanson J (2010c) Extremely low frequency electric fields and cancer: assessing the evidence. Bioelectromagnetics 31(2): 89-101.

Kroll ME, Carpenter LM, Murphy MFG, Stiller CA (2012) Effects of changes in diagnosis and registration on time trends in recorded childhood cancer incidence in Great Britain. Br J Cancer 107(7): $1159-1162$.

Kroll ME, Murphy MFG, Carpenter LM, Stiller CA (2011a) Childhood cancer registration in Britain: capture-recapture estimates of completeness of ascertainment. Br J Cancer 104(7): 1227-1233.
Kroll ME, Stiller CA, Murphy MFG, Carpenter LM (2011b) Childhood leukaemia and socioeconomic status in England and Wales 1976-2005: evidence of higher incidence in relatively affluent communities persists over time. Br J Cancer 105(11): 1783-1787.

Kroll ME, Swanson J, Vincent TJ, Draper GJ (2010) Childhood cancer and magnetic fields from high-voltage power lines in England and Wales: a case-control study. Br J Cancer 103(7): 1122-1127.

Murrells TP, Passant NR, Thistlethwaite G, Wagner A, Li Y, Bush T, Norris J, Walker C, Stewart RA, Tsagatakis I, Whiting R, Conolly C, Okamura S, Peirce M, Sneddon S, Webb J, Thomas J, MacCarthy J, Choudrie S, Brophy N (2010) UK Emissions of Air Pollutants 1970 to 2008. AEA Group: Harwell, UK.

Pedersen C, Raaschou-Nielsen O, Rod NH, Frei P, Poulsen AH, Johansen C, Schüz J (2014) Distance from residence to powerline and risk for childhood leukaemia: a population-based case-control study in Denmark. Cancer Causes Control 25: 171-177.

Sermage-Faure C, Demoury C, Rudant J, Goujon-Bellec S, Guyot-Goubin A, Deschamps F, Hemon D, Clavel J (2013) Childhood leukaemia close to high-voltage power lines-the Geocap study, 2002-2007. Br J Cancer 108(9): 1899-1906.

Swanson J (2008) Methods used to calculate exposures in two epidemiological studies of power lines in the UK. J Radiol Prot 28(1): 45-59.

Swanson J, Kheifets L (2006) Biophysical mechanisms: a component in the weight of evidence for health effects of power-frequency electric and magnetic fields. Radiat Res 165(4): 470-478.

Swanson J, Vincent T, Kroll M, Draper G (2006) Power-frequency electric and magnetic fields in the light of Draper et al. 2005. Ann NY Acad Sci 1076(1): 318-330.

UK Childhood Cancer Study Investigators (1999) Exposure to power-frequency magnetic fields and the risk of childhood cancer. Lancet 354(9194): 1925-1931.

UK Childhood Cancer Study Investigators (2000a) Childhood cancer and residential proximity to power lines. Br J Cancer 83(11): 1573-1580.

UK Childhood Cancer Study Investigators (2000b) The United Kingdom childhood cancer study: objectives, materials and methods. $\mathrm{Br} J$ Cancer 82(5): 1073-1102.

World Health Organization (2007) Environmental Health Criteria 238. Extremely Low Frequency Fields. WHO Press: Geneva, Switzerland.

This work is published under the standard license to publish agreement. After 12 months the work will become freely available and the license terms will switch to a Creative Commons AttributionNonCommercial-Share Alike 3.0 Unported License.

Supplementary Information accompanies this paper on British Journal of Cancer website (http://www.nature.com/bjc) 